\title{
Leer para escribir
}

\author{
Lucas Lavado Mallqui \\ Universidad San Martin de Porres \\ Edson Jorge Huaire Inacio \\ Universidad San Ignacio de Loyola
}

Durante dos años largos me fui hundiendo en las arenas movedizas de una documentación torrencial, contradictoria y muchas veces incierta, desde los treinta y cuatro tomos de Daniel Florencio O’Leary hasta los recortes de los periódicos menos pensados. Mi falta absoluta de experiencia y de método en la investigación histórica hizo aún más arduo mis días. Gabriel García Márquez: El General en su laberinto.

"[C]uanto más familiar es un concepto, más fácil es pensar en él de diversas maneras. Y esto me lleva a una importante observación: presentar múltiples versiones de un mismo concepto puede ser un método muy poderoso para cambiar la mentalidad de una persona. Howard Gardner: Mentes flexibles: El arte y la ciencia de saber cambiar nuestra opinión y la de los demás.

\section{Resumen:}

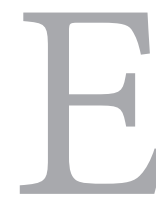

ste artículo es parte de un trabajo que los autores vienen realizando en torno a la enseñanza de la investigación en las universidades limeñas y de los manuales que circulan en nuestro medio. De cómo están relacionados con las dificultades para pensar y escribir los trabajos de investigación, desde los trabajos prácticos o monografías hasta las tesis de graduación. Las disquisiciones muchas veces farragosas de los manuales y la omisión u olvido de pautas sencillas que posibilitarían leer pensar y escribir cualquier texto de interés nos lleva a formular algunas reflexiones y mostrar algunos ejemplos libres de toda intensión de reglas a manera de recetarios.

Palabras clave: cultura, lectura, escritura, referencias APA, textos de web. 


\section{Artículos Teóricos}

\section{Introducción}

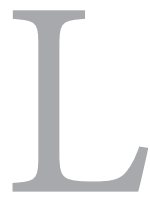

a lengua es el código de comunicación por excelencia de los humanos, pero con una precisión que es importante remarcar, el uso de la lengua hablado que es común en nuestra especie, es parte del contexto y crea contexto como signo lingüístico dado que es una herramienta de comunicación vital, la lengua hablada enfrentó y venció desde el inicio de su invención una dificultad grande: no podía sobrepasar las barreras del espacio y del tiempo. De Mauro (1980, p. 16) menciona que "sin las palabras nadie es nada, ni sabio, ni poeta, ni proverbio alguno podría elogiar el silencio". Es posible dejarse escuchar en un espacio hasta donde alcanzamos oír, pero no a diez quilómetros. También sobrepasó otra dificultad de memorización: se podía hablar con los interlocutores un día y ellos serían capaces de recordar el mensaje quizá durante los años de su vida, con los riesgos de deformarla o de perderla definitivamente. Posteriormente se inventó la escritura la cual es reciente, aproximadamente hace 2000 a.C. (Calsamiglia y Tusón, 2007).

Entonces, el invento y el perfeccionamiento de la escritura a lo largo de la historia, ha permitido salvar esas y otras dificultades, posibilitando el desarrollo de la cultura. Las prácticas que se derivan de ella, da vigor a la conciencia y son capaces de cambiar el estilo cognitivo y los modelos mentales de una organización social, de una comunidad (Calsamiglia y Tusón, 2007). La interacción entre conversación y escritura que van desde la comunidad local hasta la comunidad global ha incrementado el universo del saber. Este es un punto de referencia de la educación: si no se pone el acento en la lectura creativa y el diálogo fecundante a partir de esta lectura, no será posible mejorar los aprendizajes. Responder en la práctica qué leer y cómo hacerlo es el carburante donde se cocina el deseo de escribir.

\section{Lectura como aventura inconclusa}

Si la aventura con los libros comienza temprano, la pasión por la lectura es un premio que se gana en el camino. La búsqueda y el hallazgo de textos motivadores es otro premio que está atado al interés y la vocación. Los escritores y los investigadores son pruebas de que existen resortes ocultos que solo se pueden descubrir leyendo y estudiando en el campo académico. Lectura y escritura son como dos caras de una moneda. Nadie podría reprocharle a Truman Capote (2002) cuando responde a la pregunta ¿Lee usted mucho? 
"Demasiado, y cualquier cosa, incluida las etiquetas, las recetas de cocina y los anuncios. Soy un apasionado de los periódicos: leo todos los periódicos de Nueva York todos los días y además las ediciones dominicales y varias revistas extranjeras. Las que no compro las leo de pie en los puestos de revistas. Leo un promedio de cinco libros a la semana: una novela de extensión normal me lleva unas dos horas. Disfruto las novelas de misterio y me gustaría escribir una algún día” (p. 322).

Capote expresa una actitud y un hábito muy personal, excepcional no solo por el tipo de lectura sino por su voracidad. Los científicos que aportaron en campos especializados, no se quedaron en las lecturas de su especialidad. Charles Darwin (1993), el creador de la Teoría de la Evolución, dice en su autobiografía: "[c]on respecto a mis gustos variados, independientemente de la ciencia, era aficionado a leer libros diversos y solía quedarme durante horas sentado leyendo las obras históricas de Shakespeare" (p.12). Una primera observación acerca de nuestra educación universitaria es que está ganada y saturada por la profesionalización. Las asignaturas formativas y humanísticas son muy restringidas.

La lectura para que sea provechosa debe ser atenta, creativa y promotora. Sumergirse en la lectura con pasión, dejándose llevar por ella, es bueno, pero también es bueno salir de ella, de cuando en cuando, para valorar desde cierta distancia las ideas que se han asimilado. La lectura de aportes originales es un imperativo, pero "no toda lectura es válida por sí. Para que sea fecunda, dé frutos abundantes, debe ser crítica, o sea, cuestionadora de todo. Es menester que, como el fuego, queme la paja, purifique el oro" (Eco, 1984, p. 133). La crítica hacia la lectura deberá ser racional. En las aulas universitarias esta exigencia requiere del profesor un doble esfuerzo: seleccionar textos relevantes y organizar antologías debidamente sincronizadas, que requieren tiempo y dedicación. Carecemos en nuestro medio universitario de textos seleccionados por áreas disciplinares. Abunda el plagio.

Nuestras relaciones con los libros y la cultura no son saludables y alentadoras. Las respuestas de los alumnos frente a los textos relativamente extensos y especializados, es francamente hostil. El terreno ha sido totalmente invadido y ganado por los tuiteros. El periodista César Hildebrandt (2015) denuncia una realidad dramática pero cierta con respecto a los peruanos quienes debemos asumirla sin concesiones a las explicaciones auto exculpatorias, si de verdad queremos superar nuestras más odiosas lacras. 


\section{Artículos Teóricos}

“Tengo la convicción de que el cociente intelectual peruano disminuye día a día.

Hablamos mal, escribimos peor, nos comunicamos desde la ignorancia.

Somos cada día más perezosos para leer, más renuentes para entender, más lentos para captar.

$[\ldots]$

Pero volvamos al tema inicial de esta columna. A mí me da pena patriótica decirlo, pero la verdad es que siento, con toda nitidez, que el porcentaje de brutos se ha incrementado exponencialmente en el Perú [...].

¿Dónde empezó? En la Educación pública no hay duda. Su degradación lleva décadas y estamos pagando ahora el costo de haberla desatendido tanto tiempo.

¿Y el papel de la radio y la televisión? Ha sido decisivo. Son maquinarias perfectas de estupidización colectiva [...]. Por eso es que los gimnasios están llenos y las bibliotecas vacías. El mensaje es claro: la imbecilidad es rentable" (p.8.)

\section{Las motivaciones para escribir}

La lectura es madre de la escritura. Cómo se escribe y para quién se escribe, son preguntas que se pueden contestar, una y otra vez, recurriendo a quienes saben escribir. Si es que existe alguna regla, se encontrará en aquellas experiencias de los que con su oficio han creado mundos literarios y científicos o ambos. A escribir se aprende escribiendo y este trabajo está librado casi totalmente a factores motivacionales y a modelos tomados de nuestros héroes y líderes preferidos. La proliferación incontenible de jueces, fiscales y rectores plagiadores, es la consecuencia de una educación universitaria ausente de los libros.
No se ha inventado aún reglas formales de aplicación general, que no sean las reglas gramaticales. Algunos autores de manuales para aprender a investigar y a escribir, cuando establecen normas dicen muchas veces cosas muy extrañas y difíciles de ponerlas en práctica. La larga enumeración de normas para leer que yacen en los manuales que muchas veces se les obligan a comprar a los estudiantes persiste con terquedad. La respuesta de Truman Capote (2002) a una entrevistadora es apenas un ángulo cargado de emociones más que de normas o reglas. Quizá sirva para escandalizar a los maestros del colegio. 
¿Podría usted mencionar algunos de sus hábitos de trabajo? ¿Usa usted un escritorio? ¿Escribe a máquina?

Soy un autor completamente horizontal. No puedo pensar a menos que esté acostado, ya sea en la cama o en un diván y con un cigarrillo y café a la mano. Tengo que estar chupando y sorbiendo. A medida que avanza la tarde, cambio de café a té de menta y de jerez a martinis. No uso máquina de escribir. No al comienzo. Escribo mi primera versión a mano (con lápiz). Después hago una revisión completa, también a mano. Esencialmente, me considero un estilista, y los estilistas son notoriamente proclives a dejarse obsesionar por la colocación de una coma y por el peso de un punto y coma. Las obsesiones de este tipo, y el tiempo que me quitan, me irritan hasta lo indecible (pp. 323-324).

Lo que afirma Capote no es un recetario. Quien comienza a escribir es porque posee motivaciones para hacerlo y ese camino se emprende guiado por un interés, es más, un "ferviente interés". La necesidad de escribir tiene que ver con la necesidad de comunicarnos con los demás. Pero existe un ritual universitario y académico: el cumplir con la de presentación de trabajos y monografías, pero, inclusive en este campo, el imperativo está ligado a la vocación por la carrera o la profesión elegida. Los resultados de esta empresa son más exitosos cuando los estudiantes eligen libremente los problemas o temas de su investigación.

La vocación es pues algo que siempre está en el fondo de esta tarea. Ni las carencias económicas son impedimentos. Dice Faulkner (2002), que el verdadero creador "no necesita libertad económica. Todo lo que necesita es lápiz y un poco de papel” (p. 170). En muchos casos, podría ser un buen pretexto decir que se requiere una técnica o un método. Frente a este pretexto el mismo Faulkner es tajante: “[s] i el escritor está interesado en la técnica, más vale dedicarse a la cirugía o a colocar ladrillos. Para escribir una obra no hay ningún recurso mecánico, ningún atajo. El escritor joven que sigue una teoría es un tonto. Uno tiene que enseñarse por medio de sus propios errores; la gente solo aprende a través del error" (Faulkner, 2002, p.174).

Escribir para aprender asignaturas no debe ser tomado como tarea gravosa. Pero ¿cómo escribir los papers, ponencias, artículos, proyectos y tesis sin el peso de las exigencias metodológicas? Se trata, en cierto modo, de utilizar la escritura como estrategia de aprendizaje. Quien escribe una carta, un 


\section{Artículos Teóricos}

informe, una reseña, una monografía, tendrá que echarse a pensar de manera ordenada. Para lo cual tendrá que haber leído y hecho sus fichas y sus resúmenes de lecturas. Tendrá que haber asimilado algunas ideas y realizado algunas prácticas y, por cierto, haber entendido algunos conceptos, para luego organizarlos y escribir su relato. Algunos maestros condenan, sin más, la "memorización" y muchos alumnos enfrentados a los textos suelen decir “ ¿tengo que memorizarlos"? La respuesta es simple: no hay aprendizaje sin memoria.

¿Qué requisitos exige el escribir? El deseo de hacerlo, ideas y palabras apropiadas, para comenzar. Pero estos ingredientes no podrán surgir de un vacío total de conceptos y experiencias. La fuente está en la bibliografía consultada, pero no en todas en la misma medida, hay textos basura que impiden pensar y extravían al lector.

Para escribir, se requiere un esquema. Los esquemas no son invariables, son modificables durante la escritura. La bibliografía seleccionada siempre será una buena guía, un buen libro o un artículo científico relevante, serán fuentes de esquemas, pautas, citas, referencias y datos. Los textos bien escritos son los mejores maestros que luego de leerlos y entenderlos, después de un tiempo no se sabe cuánto, el deseo de expresar las propias ideas surgirá de un modo espontáneo. A veces inesperado. O quizá nunca.

\section{Los ejemplos ayudan, no son recetarios}

Losbuenos textos, sobre todoparalos jóvenes universitarios, son aquellos que contienen ideas fecundas, inspiran y emocionan. Está probado que los aprendizajes son mejores si van acompañados de emociones. En un curso internacional en Lima, Jesús Mosterín (2002) le responde al filósofo peruano David Sobrevilla -quien le pide que le diga cuál es estilo de vida de los españoles de hoy- su respuesta ¿pude inspirar algunas ideas al lector? 
"Yo conozco peruanos que tienen estilos de vida totalmente distintos y desde luego les aseguro que el estilo de vida mío no tiene nada que ver con el estilo de vida de la mayoría de los españoles. En España hay estilos de vida totalmente distintos y opuestos desde todos los puntos de vista. Quienes tenemos estilos de vida somos nosotros, y yo les invito a todos ustedes, y me invito a mí mismo, le invito a David Sobrevilla, a que pensemos que la vida es corta, que el vivir nuestra vida de la mejor manera posible, el vivir nuestra vida de la manera más creativa posible, el inventar nuestra vida de la manera más imaginativa posible, es la obra de arte más importante que tenemos en nuestras manos: nuestra propia vida. Pero no nos engañemos, nadie nos va a vivir nuestra propia vida, ningún pueblo, ni ninguna nación, ni ningún grupo va a vivir nuestra propia vida. Nuestra propia vida la vamos a vivir y la vamos a morir cada uno de nosotros, y cada uno de nosotros es el verdadero artista que logrará vivir y no logrará vivir su propia vida con más o menos estilo. No sé si al final lograremos el estilo, pero si logramos el estilo, lo lograremos cada uno de nosotros, y nadie, ni siquiera el gobierno que nos da un pasaporte, nos va a librar de esta ardua tarea" (p. 338).

Existen textos motivadores, que quedan fijados en la memoria del lector, ¿de qué depende este hecho? De las experiencias anteriores, de las informaciones previas, también de las expectativas futuras, $y$, en fin, de las necesidades, deseos e intereses profundos.

Repetimos, aprenden mejor las personas que encuentran libros que le suscitan emociones. El escritor Henry Miller (1973) dice en una carta: "[e]l motivo de que viva en constante estado de efervescencia se debealos librosque estoyleyendo, principalmente mis viejos libros favoritos. Todo me nutre y me estimula. Al principio pensaba escribir un libro chico; ahora me parece que será un tomo voluminoso. Día tras día anoto en mi libreta algunos títulos más que recuerdo” (p.188).
¿Tiene usted alguna lectura favorita? ¿Tiene autores preferidos? Creo que estas son preguntas que no todos pueden contestarlas de inmediato, sin embargo, es exigencia impostergable en la universidad. Las normas sobre la lectura y las obligaciones impartidas a los maestros no dan resultados porque no es un ejercicio o tarea administrativa, tiene que ver más bien con su formación, la calidad de sus aprendizajes previos y su autoestima.

La adquisición de destrezas para escribir, requieren ejercicio permanente y cooperación académica. Esto, no es algo que se aprenderá sin demora y desde el inicio de la matrícula. Como lo ha dicho uno de los más grandes escritores latinoamericanos: "[r] equieren poca 


\section{Artículos Teóricos}

magia y mucho trabajo duro. Y, como Proust, creo que para escribir hace falta un diez por ciento de inspiración y un noventa por ciento de transpiración" (García Márquez, 1996 p. 150). Una actividad fascinante, de la que nadie quedará indiferente. El mismo García Márquez después de haber publicado El general en su laberinto, dijo que había leído todo lo que se había escrito hasta ese entonces sobre Simón Bolívar. Un desmentido para quienes piensan que para escribir novelas no es necesario investigar.

En los datos sobre grandes escritos subyacen afectos y pasiones que acucian y empujan ir hacia adelante. Norman Mailer (1981) comenzó a escribir a los siete años y en una entrevista acerca de su oficio asume que la visión y la metodología son esenciales en el oficio del escritor. Como los grandes escritores del siglo XX expresa su condena a la cobardía para defender la verdad a tal punto que "uno se enamora de la verdad al verla en la punta de un lápiz. Ese es uno de los pocos placeres de la vida; un placer por sí y en sí mismo" (p. 250).
Mailer no solo ha escrito novelas sino reseñas, artículos y ensayos.

Algunos, pese a los bellos ordenadores, prefieren escribir a mano. Otros siguen con su máquina de escribir del siglo pasado, que hoy es ya un objeto de museo. La avasalladora presencia del ordenador es hoy ineludible, permite no solo corregir sino reeditar indefinidamente. ¿Corregir? Ernst Hemingway, sorprende cuando suelta el dato de que la última página de Adiós a las armas la rehízo 39 veces. Saber esto no es un consuelo, significa que para escribir hay que practicar y practicar. Volviendo a Eco (2009), su libro Cómo se hace una tesis la escribió, con la antigua Olivetti, que en sus muchas reediciones sus tipos le letras siguen inconfundibles. Los que escriben corrigen, algunos buscan la perfección y logran alcanzarlo. Los tipos de faltas y dificultades son inabarcables, lograr minimizarlas, ese es un gran desafío. Finalmente, pueden ser de utilidad los consejos prácticos y sencillos del filósofo español Jesús Mosterín (1993).

\footnotetext{
"Si leemos una carta con una pocas faltas de ortografía, a pesar de todo la entendemos. Pero conforme las faltas se multiplican, la lectura se hace más penosa. A partir de un cierto número, la carta puede resultar incomprensible. Lo mismo pasa con las erratas de un libro. Conviene evitar las faltas de ortografía y las erratas para facilitar el proceso de la comunicación. Si escribimos es para comunicarnos. Y cuanto más uniformemente escribamos todos los hablantes de la misma lengua, tanto más fácil, rápida y eficaz será la comunicación" (p. 165).
} 


\section{Artículos Teóricos}

\section{Sobre referencias y transcripciones}

Investigar es buscar datos e información relevante para elaborar nuevos conocimientos. Para elaborar nuevos conocimientos es necesario pensar $y$, pensar en ciencias solo es posible a partir de donde otros pensaron. Los resultados de esta búsqueda se escriben en forma de papers, monografías, tesis, etc. Y estas tareas requieren hacer transcripciones relevantes, citas y referencias siguiendo pautas establecidas que, en este caso puede ser el estilo de la APA (Asociación Psicológica Americana). La lectura sistemática es indispensable. Valen aquellos ejemplos realmente existentes, no ficticios.

\section{Referencia de libro:}

Bunge, M. (2009). Filosofía política: Solidaridad, Cooperación y Democracia Integral. Barcelona: Gedisa.

\section{Referencia de capítulo de libro:}

Atienza, M. (2014). La dogmática como tecnopraxis. En Á. Núñez (coord.). Modelando la ciencia jurídica (pp.115-159). Lima: Palestra.

\section{Referencias de artículo de revista:}

Esquivel, V. (2015). El cuidado: de concepto analítico a agenda política. Nueva Sociedad, 1(256), 63-74.

\section{Referencias de artículo de periódico:}

Solana, J. (2015, mayo 8). Cuando el ciberespacio es vulnerable. El País, p.31.

\section{Documentos de internet:}

Recomendación 1: en internet se pueden encontrar tanto información valiosa como inútil. Esta constatación obliga a utilizar criterios que permitan distinguir qué es valioso y qué no lo es.

Recomendación 2: la impresionante información existente en internet está fuera del alcance de una sola persona. Demasiada información impide pensar. Es indispensable elegir y estudiar información valiosa y dentro de un esquema de trabajo.

\section{Referencias de publicaciones en la web:}

Area, M. (2005). Tecnologías de la información y comunicación en el sistema escolar. Una visión de las líneas de investigación. Revista Electrónica de Investigación y Evaluación Educativa, 11(1), 1-2. Recuperado de http://www.uv.es/ RELIEVE/v11n1/RELIEVEv11n1_1.htm

Sautter, G. (1976). Algunas reflexiones sobre la geografía. Revista Internacional de Ciencias Sociales 1 (0), 7-25. Recuperado de http://unesdoc.unesco.org/images/0015/001562/156245so.pdf 
Transcripciones textuales de textos de la web:

Existen sitios web que contienen información valiosa, como se ha dicho antes, no solo por el prestigio de los autores, sino de las revistas, periódicos y libros que han ganado reconocimiento en la comunidad científica.

\section{Ordenador como máquina de escribir:}

"Un programa de tratamiento de textos convierte al ordenador en algo parecido a una máquina de escribir, pero provista de unos poderosos recursos y una gran flexibilidad. La pantalla sustituye a la hoja de papel en blanco, y cada vez más, la imita. Algunas marcas suministran pantallas del tamaño de una hoja DIN A-4 real"

Bartolomé, A. (2006). El ordenador como herramienta. Recuperado de http:// www.lmi.ub.es/personal/bartolome/ articuloshtml/herramienta_89/index. html

\section{Cultura hacker: redes y autoridad}

"La cultura hacker se organiza en redes de colaboración en Internet, aunque de vez en cuando hay algunos encuentros presenciales. Distintas líneas tecnológicas se agrupan en torno a grupos cooperativos, en los cuales se establece una jerarquía tecnológica según quiénes son los creadores de cada programa original, sus mantenedores y sus contribuidores. La comunidad suele reconocer la autoridad de los primeros innovadores, como es el caso de Linus Torvalds en la comunidad Linux. Pero sólo se reconoce la autoridad de quien la ejerce con prudencia y no la utiliza para su beneficio personal."

Castells, M. (2001). Hackers, crakers, seguridad y libertad. Lección inaugural de curso académico 2001-2002 de UOC, p. 1. Recuperado de http://www.uoc.es/web/ esp/launiversidad/inauguralo1/hackers. html

\section{Conclusión}

El cultivo de la expresión oral y escrita es condición básica de la investigación. La adquisición de destrezas para escribir depende de la calidad de la lectura. La enseñanza de reglas para escribir e investigar no garantizan su aprendizaje. Es necesario revisar ejemplos, estudiarlos, analizarlos críticamente y comenzar a pensar a partir de estos modelos, luego escribir y revisar sin pausa hasta alcanzar destrezas básicas de claridad y precisión. Sin embargo, las reglas sencillas sobre referencias, transcripciones relevantes y citas pertinentes, solo será posible haciendo tareas básicas de manera disciplinada y persistente. Internet es un apoyo a condición de diferenciar la información chatarra de la valiosa. 
Artículos Teóricos

\section{CCSS: influye o no en el diseño de políticas:}

"Con frecuencia los gobiernos afirman que les gustaría utilizar resultados de investigaciones creíbles y relevantes para tomar decisiones informadas y para enriquecer sus elecciones sobre política pública. Sin embargo, tanto la cultura de investigación gubernamental como el contexto político influyen en el grado en que la investigación incide en las políticas. Esto significa que la relación entre la investigación y el diseño de políticas públicas raramente es lineal. En muchos países, los creadores de políticas públicas toman sus decisiones con base en la intuición, la ideología, o la presión por parte de diferentes grupos de interés. En numerosas ocasiones hacen referencia a la investigación únicamente para justificar o legitimar sus elecciones. Pero en las sociedades democráticas, los conceptos, teorías y resultados de las investigaciones se filtran entre el público informado y los medios, y después de muchos años, terminan influyendo en los debates y las decisiones sobre política pública. En este caso los resultados de las investigaciones influyen en las decisiones, pero rara vez lo hacen inmediatamente"

Unesco (2011). Informe sobre las ciencias sociales en el mundo. Las Brechas del conocimiento. México: autor, p.336.

http://unesdoc.unesco.org/images/0021/002173/217366s.pdf

\section{Referencias}

Calsamiglia, H. y Tusón, A. (2007). Las cosas del decir. Manual de análisis del discurso. Barcelona: Ariel.

Capote, T. (2002). Entrevista de Pati Hili. En, El oficio del escritor (6 ${ }^{a}$. Ed.). México D.F: Era.
Darwin, C. (1993). Autobiografía. Madrid: Alianza.

De Mauro, T. (1980). Guía para el uso de la palabra. Barcelona: Del Serbal, 1982.

Eco, U. (2002). Sobre literatura. Barcelona: RqueR. 


\section{Artículos Teóricos}

Eco, U. (2009). Cómo se hace una tesis. Técnicas $y$ procedimientos de estudio, investigación y escritura (6 ${ }^{\mathrm{a}}$. ed.). Barcelona: Gedisa.

Faulkner, W. (2002). Entrevista de Jean Stein Vanden Heuvel. El oficio del escritor (6a. Ed.). México D.F: Era.

García, G. (1996). Entrevista. Oficio del escritor. Buenos Aires: El Ateneo Pedro García.

Hildebradt, C. (2015). Cociente intelectual de los peruanos. Hildebrandt en sus trece, 241, 8.
Mailer, N. (1981) Entrevista de Steven Marcus. En G. Plimpton (editor), Hablan $l \quad o \quad s$ escritores (pp. 219-251). Barcelona: Kairós.

Miller, H. (1973). Los libros en mi vida. Buenos Aires: Siglo Veinte.

Mosterín, J. (1993). Teoría de la escritura. Barcelona: Icaria, S.A.

Mosterín, J. (2002). Epistemología y racionalidad (2 $2^{\text {a }}$ ed.). Lima: Fondo Editorial de la UIGV. 